\title{
O POLICIAMENTO AMBIENTAL E O TRÁFICO DE ANIMAIS SILVESTRES NO OESTE PAULISTA
}

\section{Adilson Luís Franco Nassaro ${ }^{1}$}

RESUMO: o artigo analisa o trabalho do policiamento ambiental e a constatação da permanência do tráfico de animais silvestres no oeste do Estado de São Paulo nos dez anos seguintes à entrada em vigor da "Lei de Crimes Ambientais" (Lei no 9.605, de 1998). O texto descreve a dinâmica criminal em um ciclo - atos de caça, transporte, cativeiro e negociação - com base no estudo dos registros policiais dos boletins de ocorrência ambiental em situações relacionadas ao comércio ilegal. Ainda, a pesquisa buscou uma reconstituição aproximada das tensões entre a estrutura de fiscalização e a desafiadora prática ilícita que se perpetua, revelando, por outro lado, uma mudança de postura policial para priorizar ações preventivas no amplo conceito de educação ambiental.

Palavras-chave: Tráfico de animais silvestres. Policiamento ambiental. Fauna.

\section{INTRODUÇÃO}

O estudo dos registros policiais dos boletins de ocorrência ambiental no período de 1999 a 2009 e que resultaram apreensão de animais silvestres em situações relacionadas ao comércio ilegal no oeste do Estado de São Paulo possibilitou a descrição da dinâmica criminal em um ciclo do tráfico caracterizado pelos atos de caça, pelo transporte, pelo cativeiro e pela negociação.

\footnotetext{
${ }^{1}$ Mestrando em História, UNESP de Assis (História Ambiental); bacharel em Direito, com especialização em Processo Penal; major da Polícia Militar de São Paulo; e-mail: nassaro@policiamilitar.sp.gov.br.
} 
No propósito de pesquisa, foram analisadas cada uma das fases criminosas, suas particularidades e desdobramentos quanto à irregular exploração e apropriação do recurso natural no período indicado. Esse momento contemporâneo coincide com os primeiros anos de vigência da Lei dos Crimes Ambientais (Lei o 9.605, de 1998) e também contempla a evolução do esforço estatal de prevenção e de repressão presente nas estratégias e ações voltadas à proteção da fauna silvestre.

Sobreveio, para tanto, a dificuldade de reunião dos documentos, pela dispersão das vinte e três sedes envolvendo companhias, pelotões e grupos policiais na ampla área do $2^{\circ}$ Batalhão de Polícia Ambiental de São Paulo ( $2^{\circ}$ BPAmb), cada qual com arquivo próprio. Como fonte primária, enfim, foram estudados 327 boletins de ocorrência em registros de ações envolvidas direta ou indiretamente no tráfico de animais silvestres.

\section{ATOS DE CAÇA: INÍCIO DO CICLO DO TRÁFICO E SUA COIBIÇÃO}

A caça não é fenômeno recente ou localizado. A ação antrópica que evidencia a superioridade do homem diante dos outros animais, não somente pela capacidade física, é tão antiga quanto a própria existência da espécie humana. Ainda, no meio natural a caça é anterior ao homem e, como decorrência da cadeia alimentar, o animal mais forte caça o mais fraco - ou o menos capaz - para se alimentar. No território que se denominou brasileiro, múltiplas utilidades alcançadas pela captura de espécimes silvestres perpetuaram o extrativismo animal em um espaço geográfico que, além de imenso, ainda comportava notável concentração de diversidade biológica imediatamente reconhecível em sua ocupação.

No caso do espaço territorial que compreende o atual Estado de São Paulo, além da grave pressão sobre os ecossistemas pela expansão das plantações de café favorecidas pelo avanço da ferrovia já no início do século $X X$, a caça constituiu fator que marcou a sua ocupação e que ainda se manteve por longo tempo. Todavia, como se confirma no resultado do recente trabalho de fiscalização ambiental, a maior parte dos animais silvestres atualmente traficados em São Paulo é capturada longe do local de transporte, de cativeiro ou de negociação. Veremos isso. 
A "Polícia Militar Ambiental" ou "policiamento ambiental" de São Paulo, como ramo de atividade especializada da Polícia Militar paulista, é o título contemporâneo da estrutura que se manteve em funcionamento com as mesmas atribuições definidas em 1949, quando surgiu a Polícia Florestal com homens da Força Pública, somadas aos outros encargos advindos ao longo das décadas seguintes ${ }^{2}$.

O órgão policial ambiental manteve ao longo das últimas décadas do século XX a básica coibição de atos ilegais de caça - vinculados ou não ao tráfico - e ainda a prestigia. Os atos de caça voltados ao tráfico de animais silvestres são característicos de "caça profissional", expressão empregada na lei para designar a caça comercial, ou caça com propósito de negociação do produto (resultado da atividade) em oposição à "caça por esporte" ou à "caça de subsistência", justificando-se no primeiro caso o aumento de pena previsto no parágrafo $5^{\circ}$, do artigo 29 , da Lei $n^{\circ} 9.605$ de $1998^{3}$.

No entanto, a prova do liame entre a caça de animal silvestre e o propósito de comércio raramente é obtida tanto no momento dos registros e das investigações policiais quanto na posterior etapa processual do ciclo da persecução penal. Ocorre que a caça, o transporte, o cativeiro e o negócio irregulares envolvendo animal silvestre sempre foram usualmente concretizados de forma discreta ou dissimulada, o que denota o conhecimento geral do caráter ilícito das condutas correlatas.

Em São Paulo, excetuada a caça esportiva que a Constituição Estadual proibiu a priori no seu artigo 204 e a profissional que já era proibida em todo o país desde 1967, as demais modalidades remanesceram como uma possibilidade dependente de autorização específica (a "caça de subsistência", a "caça de controle" - para diminuição de animais considerados nocivos - e a "caça para fins científicos"). A necessidade de permissão, licença ou autorização prevista na Lei dos Crimes Ambientais de 1998, em situações extraordinárias, veio a confirmar a regra da proibição da caça no país ${ }^{4}$.

\footnotetext{
2 "Polícia Militar" é nome da milícia paulista a partir de 1970, com a unificação da então Força Pública com a Guarda Civil, concretizada pelo Decreto-Lei Estadual no 217, de 08 de abril de 1970.

${ }_{3}$ A pena para os crimes previstos no artigo 29 da Lei ํㅜ 9.605 de 1998 (a chamada "Lei dos Crimes Ambientais"), dentre eles o de caçar, é de detenção de seis meses a um ano, e multa (delito considerado, portanto, de menor potencial ofensivo nos termos da Lei 9.099, de 1995). Todavia, conforme artigo 15, inciso II, da mesma Lei, existem circunstâncias que agravam a pena, quando não constituem ou qualificam o crime, entre outras: "ter o agente cometido a infração: a) para obter vantagem pecuniária (...) (grifos nossos).

${ }^{4} \mathrm{O}$ próprio artigo 29 , da Lei no $9.605 / 98$, principal conjunto de normas de proteção à fauna silvestre, estabelece em seu caput a definição da conduta criminosa como "Matar, perseguir, caçar, apanhar, utilizar
} 
Observando-se os dados do $2^{\circ}$ BPAmb, em sua área de atuação que cobre todo o oeste paulista ${ }^{5}$, verificou-se que no período de 1999 a 2009 os seus policiais foram responsáveis pela lavratura de 1.891 autuações ambientais em ocorrências relacionadas à fauna silvestre e, desse total, 897 referem-se à constatação da prática de atos de caça clandestina, ou seja, $47,4 \%$ deles $^{6}$.

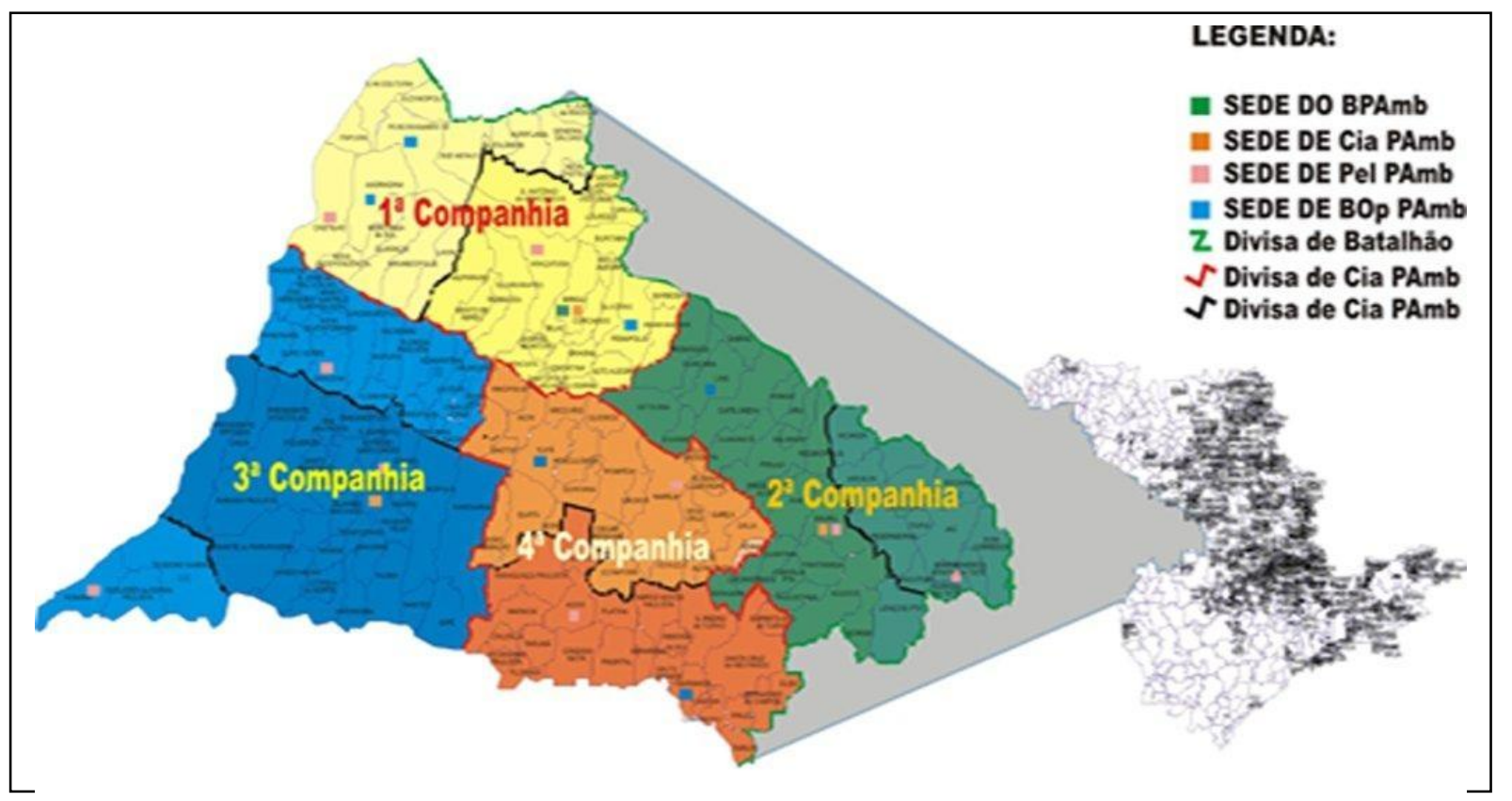

A repressão à caça ilegal significou, mesmo que de modo não planejado, um caminho para coibir o tráfico de animais silvestres, mas não o único como se verá. Apesar do grande número de ocorrências que resultaram apreensão de animais silvestres envolverem atos de caça nos anos seguintes à vigência da Lei oㅡ 9.605 de 1998,

espécimes da fauna silvestre, nativos ou em rota migratória, sem a devida permissão, licença ou autorização da autoridade competente, ou em desacordo com a obtida" (grifo nosso).

${ }^{5} \mathrm{O} 2^{\circ}$ BPAmb - sede na Travessa Marechal Deodoro, 107, Centro, Birigui/SP - é um dos quatro atuais batalhões integrantes do Comando de Policiamento Ambiental (CPAmb). Responsável pela fiscalização na área de 186 municípios, que corresponde aproximadamente a um terço do território de São Paulo. Quanto ao efetivo, 379 policiais trabalham distribuídos em quatro Companhias operacionais (Cias): Birigui, Bauru, Presidente Prudente e Marília. Cada Cia possui Pelotões (Pel) e Bases Operacionais (BOp), com áreas territoriais próprias de atuação.

${ }^{6}$ O levantamento foi realizado pelo Sistema de Administração Ambiental (SAA). Instituído no final da década de 1990, que centraliza as informações das ocorrências e o resultado das ações e operações policiais desenvolvidas, com registros diários realizados por operadores de cada sede de Pel ou de BOp. 
numericamente os animais apreendidos em São Paulo no período em análise foram capturados, em sua maioria, em outros Estados em razão da sua distribuição geográfica natural abrangente ${ }^{7}$.

Poder-se-ia imaginar, a partir de um dado significativo - quase metade das autuações por ato de caça - que o tráfico se mantém pela circulação de animais caçados no próprio Estado, mas as apreensões revelam que não é isso que ocorre. A identificação das espécies com maior número de animais apreendidos em território paulista nos cinco primeiros anos do período em análise indica que os passeriformes constituíram o principal alvo dos traficantes, somando $98 \%$ das apreensões, seguidos dos répteis e mamíferos. Ainda: as dez espécies mais traficadas possuíam distribuição geográfica em outros Estados, especialmente do Norte e Nordeste ${ }^{8}$.

Como pode isto ocorrer? A resposta parece clara: com a rápida diminuição dos hábitats de animais silvestres na área que mais velozmente se desenvolveu no país, o Estado de São Paulo assumiu a condição de consumidor de espécimes caçados em outros Estados da Federação. Não somente pela diminuição dos hábitats, mas especialmente pela grande concentração populacional local, formadora da demanda. Quanto às espécies passeriformes com maior quantidade de apreensões, a explicação justifica-se pelo interesse do mercado clandestino em pássaros canoros que podem ser transportados em pequenos espaços, até para compensar a desvantagem do seu preço individual - menor em relação a outros animais silvestres de maior porte. Por esses motivos, é compreensível que as apreensões mais expressivas, em números de espécimes, tenham ocorrido não durante a fase da caça, mas durante o transporte.

Enfim, a coibição da caça irregular em São Paulo não se mostrou suficiente para enfrentamento do tráfico de animais silvestres em face dos dispositivos legais que regulamentaram, restringiram ou mesmo proibiram os atos de caça em suas diversas

\footnotetext{
${ }^{7}$ Do total de 13.952 autuações registradas no período de 1999 a 2009 no Sistema de Administração Ambiental (SAA), do CPAmb, relacionadas à fauna no Estado de São Paulo, constatou-se que $7.981(57,2 \%)$ referem-se a atos de caça ou maus-tratos; 459 referem-se a transporte irregular; 4.850 referem-se a animais em cativeiro e 662 referem-se a atos de negócios envolvendo animal silvestre (Fonte: CPAmb).

${ }^{8}$ As dez espécies com maior número de espécimes apreendidos em São Paulo, na ordem indicada pelo CPAmb, são as seguintes: canário-da-terra, coleira-baiano, picharro, tico-tico, azulão, pintassilgo, pássaro-preto, curió, bigodinho e galo-de-campina (SÃO PAULO. Governo do Estado de São Paulo. Secretaria Estadual do Meio Ambiente. Polícia Militar Ambiental. Tráfico de animais da fauna silvestre nacional: Dados Estatísticos e Estratégias Operacionais 2001 - 2005. São Paulo: Polícia Militar Ambiental, 2005, p. 20).
} 
modalidades e especificidades. A versatilidade e popularização dos meios de transporte, especialmente o rodoviário a partir da década de 1950, viabilizaram a negociação do animal nos maiores centros consumidores, muito longe dos locais em que se realizava a captura, constituindo fator decisivo para a formação e especialização de grupos organizados em ação criminosa.

\section{TRANSPORTE: A MOVIMENTAÇÃO DO CRIME E DO PODER PÚBLICO}

Apesar do aparato legal proibitivo, a prática do tráfico de animais silvestres evoluiu junto com o aumento da eficiência dos meios de transporte e a popularização do veículo automotor. Surgiram divisões e até terceirizações de tarefas, com o aprimoramento da dissimulação do transporte para manter o lucro e, com isso, a compensação do risco das penas inerentes às condutas criminosas.

Depois do caçador, aparece a figura do "transportador" sob suas formas: como atravessador, no caso de revenda pessoal do objeto do tráfico; e como "mula", quando contratado por organização criminosa para apenas assumir o risco do transporte em troca de pagamento previamente combinado. Com o emprego das "mulas", a organização do crime relacionado aos animais silvestres se moldou à semelhança daquela dedicada ao comércio de drogas ou de armas, modalidades comuns de tráfico ilegal e de maior impacto nas últimas décadas ${ }^{9}$.

Ocorrências registradas revelam o usual transporte de animais silvestres pulverizado em veículos diversos, diminuindo-se as distâncias entre os locais de captura e os centros consumidores, em conduta vinculada ou não ao crime organizado. Para o traficante, a possibilidade de ser surpreendido em uma fiscalização policial passou a representar o risco do negócio, calculado junto com os lucros auferidos. Também, percebese nos registros policiais que os animais são transportados de forma dissimulada e

\footnotetext{
${ }^{9}$ A expressão "mula" foi empregada inicialmente para designar em linguagem policial a pessoa que transporta drogas na terceirização de serviços da organização criminosa que cresceu vertiginosamente nos anos 1980 . Passou a comportar em seu significado, desde a década de 1990, toda pessoa que transporta ilegalmente qualquer objeto de ilícito do local de origem para entrega ao vendedor - e não diretamente ao comprador -, representando o envolvimento no crime organizado em sua fase intermediária, da movimentação (NASSARO, Adilson Luís Franco. Busca em ônibus rodoviário: proposta de procedimento-padrão, São Paulo: CAES. 2008, p. 29).
} 
raramente o infrator assume seu envolvimento com o tráfico ilícito, apesar da constatação do transporte irregular, circunstância que já materializa a infração e o crime ambiental ${ }^{10}$. A rigor, a responsabilização penal resultará das provas reunidas durante a própria ação policial, como o termo de apreensão, a declaração dos policiais, eventuais fotos e documentos juntados.

O fato de que o transportador não colabora, em regra, com informações que possam elucidar a exata origem e o destino dos animais traficados impede uma análise minuciosa dos trajetos realizados, restando o diagnóstico dos locais de possível apreensão - pelas ocorrências mais recentes - e que podem direcionar o trabalho de prevenção policial, dinâmico na sua essência. Desse modo, estudos revelam que parte dos animais e seus produtos e subprodutos segue para os grandes centros urbanos (mantendo-se também o comércio local ou regional em pequena escala), enquanto outra parte chega aos portos e aeroportos para alcançar compradores em outros países, o que caracteriza um tráfico voltado ao público interno do país e outro voltado ao interesse internacional ${ }^{11}$. Em ambos os casos, a dinâmica do crime representada pelo movimento na fase do transporte acompanha o contraste entre os miseráveis núcleos de extrativismo animal e os abastados pontos de entrega no pólo consumidor.

Especialmente no momento do transporte, tem sido identificado também o crime de crueldade contra os animais, associado ao tráfico, e, em vários casos, a formação de quadrilha na circunstância de criminosos agindo em unidade de propósitos para completar o ciclo do comércio ilícito ${ }^{12}$.

\footnotetext{
${ }^{10}$ Fundamentação no art. 19 da resolução SMA-37/2005 (infração na esfera administrativa) e no art. 29, parágrafo 1으, inciso III da lei n. 9.605/98 (crime ambiental). A primeira norma prescreve: "Artigo 19 - Vender, expor à venda, exportar ou adquirir, guardar, ter em cativeiro ou depósito, utilizar ou transportar ovos, larvas ou espécimes da fauna silvestre, nativa ou em rota migratória, bem como produtos e objetos dela oriundos, provenientes de criadouros não autorizados ou sem a devida permissão, licença ou autorização da autoridade competente" (grifo nosso), infração que basicamente gera multa (autuação) e apreensão formalizadas em documentos próprios e em separado (artigo 5으, com valores de multa da tabela anexa à mesma resolução). A segunda norma prescreve: "inciso III - quem vende, expõe à venda, exporta ou adquire, guarda, tem em cativeiro ou depósito, utiliza ou transporta ovos, larvas ou espécimes da fauna silvestre, nativa ou em rota migratória, bem como produtos e objetos dela oriundos, provenientes de criadouros não autorizados ou sem a devida permissão, licença ou autorização da autoridade competente" (grifo nosso), crime ambiental apenado com detenção de seis meses a um ano, mas passível de transação penal, pois considerada infração penal de menor potencial ofensivo (Lei 9099/95). ${ }^{11}$ Nesse sentido, os Relatórios da RENCTAS, 2001; CPITRAFI, 2003 e CPIBIOPI, 2006.

12 No campo jurídico-penal, a crueldade, ou maus-tratos dirigidos a animais (silvestres ou domésticos) constitui conduta prevista como crime no artigo 32, da Lei no 9.605/98, com a seguinte descrição: "Praticar ato de abuso, maus-tratos, ferir ou mutilar animais silvestres, domésticos ou domesticados, nativos ou exóticos. Pena: detenção de 3 (três) meses a 1 (um) ano, e multa". Já a formação de quadrilha tem
} 
Os agentes do policiamento ambiental (quando ainda chamado "policiamento florestal e de mananciais") e do policiamento rodoviário de São Paulo ${ }^{13}$ passaram a desenvolver ações de fiscalização e operações específicas de abordagem a veículos em movimento com aparato fortalecido na condição de "bloqueio policial" a partir da década de 1980, fase em que foi criado o Tático Ostensivo Rodoviário (TOR), como resposta ao notável crescimento da criminalidade então observado especialmente nas rodovias ${ }^{14}$.

A interceptação de veículos em movimento com ordem de parada para a finalidade de fiscalização policial se consolidou como um eficaz mecanismo de prevenção e repressão aos diversos delitos relacionados ao transporte, entre eles os ambientais ${ }^{15}$. Com o aumento do rigor da legislação que reprimia o comércio de animais silvestres nas fases do ciclo criminoso - na década de 1980 - os policiais militares de cada município ou rodovia, em reforço à fiscalização já exercida pelo policiamento ambiental, passaram a contribuir com o esforço de proteção à fauna silvestre, na mesma medida da repressão ao transporte de drogas e de armas (mais comuns na movimentação do crime).

O "fator surpresa" revelou-se como grande vantagem da equipe policial diante da possibilidade de escolha de veículo em movimento que, pela discricionariedade da avaliação do agente, indicava maior probabilidade de ser utilizado na prática de ilícito - não

tipificação prevista no artigo 288, do Código Penal (Decreto-Lei no 2.848 de 1940): "Associarem-se mais de três pessoas, em quadrilha ou bando, para o fim de cometer crimes. Pena - reclusão, de 1 (um) a 3 (três) anos".

${ }_{13}$ A "Polícia Rodoviária do Estado", que integra o efetivo da atual Polícia Militar do Estado de São Paulo, foi criada em 10 de janeiro de 1948, mediante o Decreto Estadual ํㅜ 17.868, em razão da expansão das rodovias paulistas. No início, o órgão contava com guardas civis e com integrantes da Força Pública disponibilizados para os serviços de fiscalização de trânsito rodoviário, e era vinculado ao DER (NASSARO, Adilson Luís Franco. Policiamento Rodoviário: cinquenta anos com sede regional em Assis. Assis: Triunfal. 2008, p. 22).

${ }^{14} \mathrm{Na}$ medida em que os infratores da lei aperfeiçoaram seus métodos, demonstrando maior audácia na prática de delitos nas rodovias, coube aos órgãos de segurança, particularmente à Polícia Militar Rodoviária (PMRv) - primeira força na preservação e repressão do crime nas rodovias estaduais -, aprimorar sua ação combativa e elevar sua atuação preventiva em face dos crimes em movimento. Passo fundamental na valorização das intervenções policiais para enfrentar a criminalidade crescente deu-se com a criação (na estrutura da PMRv) do Tático Ostensivo Rodoviário (TOR), em 1987, mediante emprego de equipes de no mínimo três homens, bem treinados e equipados, em viaturas maiores que as tradicionais e com maior capacidade bélica: uma "força tática" nas rodovias (NASSARO, Adilson Luís Franco. Busca em ônibus rodoviário: proposta de procedimento-padrão, op. cit., p. 42).

${ }^{15}$ No dispositivo do bloqueio policial os policiais permanecem parados com esquema planejado de segurança e sinalização para esse fim. O "selecionador" procede à ordem de parada regulamentar (prevista no Código de Trânsito Brasileiro - CTB, anexo II, Lei no 9.503, de 1997) voltada ao condutor e seu veículo que serão objetos de fiscalização na esfera de polícia de segurança e, acessoriamente, também na esfera de polícia de trânsito. Essa intervenção é típica de policiamento preventivo e a restrição de direitos individuais somente é justificada em ato legítimo, de autoridade competente para realização do completo procedimento. 
necessariamente ambiental -, situação confirmada durante a revista veicular ${ }^{16}$. A intensificação de bloqueios foi mantida nos anos seguintes, incorporada à fiscalização ambiental como estratégia operacional.

No período de 1999 a 2009, a média anual de apreensões de animais silvestres em todo o estado girou em torno de 25.000 espécimes; a média anual de autuações em 800 e a média de pessoas conduzidas ao distrito policial em torno de 1.000. Do total de animais apreendidos - predominantemente passeriformes - as espécies em maior número não têm específica distribuição geográfica (natural) em São Paulo ${ }^{17}$.

Apesar de apenas 5,6\% de todas as autuações da área do 2ํㅗ BPAmb relacionadas a animal silvestre referirem-se à fase de transporte no ciclo do tráfico, a análise individual dos registros indica que as apreensões numericamente mais expressivas ocorreram exatamente nesse momento ${ }^{18}$. Se nas ocorrências de atos de caça é rara a apreensão de mais de um ou dois espécimes na posse do caçador, tal não ocorre na fase do transporte, quando é comum a apreensão de mais de uma centena de animais transportados em um mesmo veículo.

\footnotetext{
${ }^{16} \mathrm{Na}$ doutrina policial a busca ou revista veicular é considerada extensão da busca pessoal. Esta é realizada por iniciativa policial (caso de busca preventiva) e em cumprimento à ordem judicial ou após constatação de prática criminal (casos de busca processual). A busca preventiva é fundamentada no exercício do poder de polícia na área de segurança, com fulcro na missão constitucional dos órgãos policiais (artigo 144 da Constituição Federal) e a busca processual é fundamentada no artigo 240 do Código de Processo Penal (CPP) em razão da fundada suspeita. A busca preventiva, de iniciativa policial, também é justificada pela presença de fundada suspeita daquele que será submetido à revista, incluindo-se na verificação os seus pertences próximos e o veículo (NASSARO, Adilson Luís Franco. Aspectos jurídicos da busca pessoal. In: Revista A Força Policial, n. 44. São Paulo: PMESP, 2004, p. 41, também disponível em <http://jus2.uol.com.br/doutrina/texto.asp?id=9491>).

${ }_{17}^{17}$ Dados obtidos junto à Seção Operacional do Comando de Policiamento Ambiental de São Paulo.

18 De acordo com os registros do período de 1999 a 2009, o 2ำ BPAmb elaborou 1.891 autuações relacionadas à fauna e, desse total, 106 referem-se à transporte irregular. Note-se que nem todas essas infrações autuadas se relacionam com o tráfico de animais silvestres, mas dificilmente 0 transporte irregular não está associado a essa conduta criminosa.
} 
Tabela: animais apreendidos nas 327 ocorrências relacionadas ao tráfico na área do 20 BPAmb, entre 2000 e 2009, por fases do ciclo criminoso.

\begin{tabular}{cccccc}
\hline & Caça & Transporte & Cativeiro & Comércio & Total \\
\hline $\mathbf{2 0 0 0}$ & 0 & 0 & 158 & 0 & 158 \\
$\mathbf{2 0 0 1}$ & 42 & 3 & 112 & 0 & 157 \\
$\mathbf{2 0 0 2}$ & 18 & 12 & 236 & 11 & 277 \\
$\mathbf{2 0 0 3}$ & 16 & 53 & 20 & 1 & 90 \\
$\mathbf{2 0 0 4}$ & 2 & 558 & 66 & 1 & 627 \\
$\mathbf{2 0 0 5}$ & 1 & 32 & 112 & 42 & 187 \\
$\mathbf{2 0 0 6}$ & 1 & 1.167 & 337 & 2 & 1.507 \\
$\mathbf{2 0 0 7}$ & 10 & 158 & 140 & 0 & 308 \\
$\mathbf{2 0 0 8}$ & 3 & 32 & 320 & 289 & 644 \\
$\mathbf{2 0 0 9}$ & 7 & 90 & 311 & 0 & 408 \\
& $\mathbf{1 0 0}$ & $\mathbf{2 . 1 0 5}$ & $\mathbf{1 . 8 1 2}$ & $\mathbf{3 4 6}$ & $\mathbf{4 . 3 6 3}$ \\
\hline
\end{tabular}

Fonte: BOPAmb reunidos e analisados mediante pesquisa nos arquivos das sedes do $2^{\circ}$ BPAmb.

O volume de autuações ambientais e de apreensões durante a fase do transporte em veículos diversos sugere que o abastecimento dos pontos de venda clandestina é realizado por transportadores em via terrestre. Também, sugere que a ação policial nesse momento tornou-se eficaz na interceptação do traficante em movimento, rompendo o ciclo do tráfico. Por outro lado, a permanência dos registros de apreensões com a mesma característica, como comprovam as dezenas de boletins de ocorrência lavrados anualmente, indica a continuidade do modus operandi criminoso no período em estudo.

4 CATIVEIRO: A CONTINUIDADE dA PRÁtICA DELITIVA E DAS AÇÕES DE POLÍCIA AMBIENTAL

O cativeiro constitui o ponto de chegada para os animais vivos transportados no tráfico ilegal de espécimes da fauna silvestre. As apreensões policiais têm indicado que, após a movimentação criminosa dos animais retirados do meio natural, o cativeiro 
representa o seu destino, o local em que permanecem sob custódia de colecionadores, expositores ou mesmo de pessoas que pretendem mantê-los a título de "estimação" pagando menos que o preço de espécimes eventualmente vendidos por criadouros regularizados. Depois da fase do transporte, o momento do cativeiro - transitório ou definitivo - é aquele em que mais espécimes silvestres têm sido apreendidos pela intervenção do policiamento ambiental.

No ciclo criminoso, os cativeiros transitórios servem como armazéns para distribuição do objeto de ilícito. Por esse motivo, a maior parte deles se estabeleceu em cidades sedes de região, ou de micro-região, acompanhando a concentração de mais pessoas interessadas na aquisição de animais silvestres. Agentes de polícia ambiental confirmam que, não raras vezes, os cativeiros são mantidos por algum criador com registro no IBAMA, aproveitando a licença para manter - além do plantel autorizado - animais capturados irregularmente do meio natural, objetivando negociação ou utilização em cruzamentos, apesar das formas de controle disponíveis como anilhas e cadastramento de espécimes, instrumentos que se mostraram ineficazes como impeditivos dos desvios de finalidade de criadouros legalizados.

Nos últimos anos também se notou que em cidades de médio e grande porte, algumas lojas que negociam regularmente mercadorias para animais domésticos, os pet shops, passaram a acobertar o comércio clandestino de espécimes silvestres, geralmente realizado nos fundos do estabelecimento de forma dissimulada, atendendo encomendas supridas pelos cativeiros transitórios.

Apesar de raramente o responsável pelo cativeiro admitir o propósito de venda, cruzamento, ou troca irregular de espécimes, algumas circunstâncias identificam 0 envolvimento com o tráfico e o funcionamento do local como entreposto e abastecedor. Junto com o criador tem sido comum encontrar animais em quantidade e em diversidade de espécies que denunciam o interesse comercial, circunstância associada às condições de manutenção do próprio cativeiro no que toca à alimentação, luminosidade, espaço, temperatura, umidade, higienização e outras condições incompatíveis com a simples mantença "a propósito de estimação", que é o argumento normalmente utilizado na tentativa de justificar a presença de animais silvestres em cativeiro. 
Durante o período de 1999 a 2009, a destinação dos animais apreendidos constituiu a maior dificuldade no esforço de repressão ao tráfico. Sem desprezar as apreensões realizadas pelos próprios agentes do IBAMA, Órgão Executor do Sistema Nacional do Meio Ambiente (SISNAMA) em nível federal e pelos integrantes da Polícia Federal, estes em ocorrências envolvendo tráfico internacional ou mesmo interestadual, o grande volume de apreensões em todo o Brasil resultou das intervenções do efetivo das Polícias Militares, pelas ações dos seus grupos especializados os quais se convencionou chamar "policiamento ambiental". Acompanhando o modelo pioneiro de São Paulo (desde 1949), esses grupos estabeleceram-se nas últimas décadas gradativamente em todas as unidades federativas, somando no período em análise aproximadamente 10.000 homens policiais militares ambientais - em todo o país ${ }^{19}$.

Em razão do considerável efetivo e da capilaridade dessa força policial presente em todas as regiões brasileiras - em contraste com o reduzido número de agentes do IBAMA e da Polícia Federal - a sua atuação cresceu em relevância no período, absorvendo boa parte da ação de campo do órgão federal (IBAMA) nas fiscalizações para proteção da fauna silvestre. E a realidade encontrada em São Paulo não se mostrou diferente daquela encontrada nas outras unidades federativas quanto à falta de locais capacitados e disponíveis para acolhimento de animais silvestres apreendidos.

A média de 25.000 animais silvestres apreendidos por ano em São Paulo exigiu soluções locais e pontuais para o encaminhamento desses espécimes que haviam sido criminosamente retirados do meio natural e foram interceptados logo após ou durante a captura, no transporte, no cativeiro ou durante a própria negociação ilícita. Resumidamente, foram três os destinos: a permanência com o próprio autuado (casos de mantença a propósito de estimação, com o animal bem cuidado e sem risco de extinção); as entidades conservacionistas (Centros de Triagem e de manejos públicos, Parques e zoológicos municipais, Criadouros conservacionistas e Unidades regionais do IBAMA) e

\footnotetext{
${ }^{19}$ Disponível em: <http://www.pmambientalbrasil.org.br/>. Acesso em: 15 mar. 2011. Em São Paulo, no início o órgão contava com integrantes da Força Pública a disposição da Secretaria da Agricultura (que possuía o Serviço Florestal responsável pela instalação de uma "Polícia Florestal", como previa o Código Florestal de 1934); hoje, o policiamento ambiental paulista conta com 2.200 homens distribuídos entre o CPAmb e seus quatro batalhões.
} 
soltura no meio natural (no caso de animal recentemente capturado, com características de "bravio") 20.

Ainda analisadas as ocorrências, constatou-se que a fase do cativeiro foi aquela em que houve aumento expressivo de intervenções policiais e apreensões. No oeste paulista, a média mensal entre 2000 e 2004 manteve-se em 13 enquanto a média mensal de 2005 a 2009 alcançou 23. Houve estabilidade nas demais fases, notando-se que do universo de 327 ocorrências pesquisadas 184 referem-se a fiscalizações em cativeiro, o que representa $56,2 \%$ dos casos. Esse aumento de intervenções policiais explica a elevação considerável do número de animais apreendidos nos cinco anos mais recentes na área do 2ํㅡㄹ BPAmb: de um total de 4.363 espécimes, 1.309 foram apreendidos na primeira metade do período e 3.057 (70,14\%) foram apreendidos na segunda metade (de 2005 a 2009). A média mensal de animais apreendidos saltou de 261 de 2000 a 2004, para 637 de 2005 a 2009.

Por fim, um eficiente instrumento para estimular a participação da sociedade com informações foi colocado em funcionamento pelo IBAMA a partir de 2005, de modo centralizado e com atendimento ininterrupto e gratuito para todo o país: a chamada "Linha Verde". Por telefone, com a garantia do anonimato, qualquer pessoa poderia revelar dados fundamentais para a fiscalização ambiental, na sequência repassados para atuação dos próprios agentes do IBAMA ou dos policiais militares ambientais mais próximos.

Portanto, as fiscalizações certeiras com base em informações recebidas de populares constituíram resposta do poder público no esforço de coibição dos cativeiros irregulares, como estratégia para prevenção e repressão ao tráfico de animais silvestres nessa fase do ciclo criminoso.

\section{NEGociação: O ALCANCE dA VANTAGEM E A PERSPECtiva dA} EDUCAÇÃO AMBIENTAL

\footnotetext{
${ }^{20} \mathrm{Em}$ 2005, dos 25.112 animais apreendidos em São Paulo, 20,1\% permaneceram com os próprios autuados, $61,5 \%$ foram entregues a entidades conservacionistas e $18,4 \%$ foram soltos no meio natural.
} 
Ao tentar justificar a posse ou a venda do animal silvestre, geralmente o vendedor deixa transparecer um cálculo de probabilidade de êxito na iniciativa e um risco assumido: o de produzir o resultado danoso e vir a ser responsabilizado pela conduta.

A oferta de animal silvestre não constitui fato isolado no Brasil, como é possível constatar voltando-se os olhos para os meios de comunicação, particularmente o ambiente virtual da rede mundial de computadores que protagonizou no mesmo período em estudo um processo de franca expansão e acessibilidade, diminuindo distâncias entre participantes de negócios ilícitos. O próprio relatório da Comissão Parlamentar de Inquérito destinada a investigar o tráfico de animais e plantas silvestres brasileiros, a exploração e comércio ilegal de madeira e a biopirataria no país (CPIBIOPI) anexou a chamada "pasta 4" com documentos indicando ofertas de animais silvestres a venda, material posteriormente repassado para apuração de órgãos policiais. Como restou registrado nesse relatório que sintetiza os trabalhos da Comissão: "Praticamente todos os animais foram anunciados nos sites MercadoLivre.com ou Arremate.com. Os participantes das discussões são identificados pelo nome de usuário com que estão logados, o que impossibilita a identificação"21.

Os recentes estudos de teorias que buscaram determinantes da criminalidade, no propósito de oferecer subsídios para a prevenção, também se aplicam à prática de infração contra o meio ambiente, notando-se que o contumaz traficante de animais silvestres projeta uma forma de ganho constante, com a possibilidade de permanência na ocupação marginal. Na chamada "Teoria Econômica da Escolha Racional" encontra-se a explicação para a incidência criminal, quando identificado o "cálculo de probabilidades" por parte do criminoso habitual envolvido ${ }^{22}$.

Para evitar a prática criminal, cresceu no período estudado a percepção de que a polícia deveria desenvolver ações preventivas em amplo sentido voltadas àqueles que em tese não teriam suficiente conhecimento da irregularidade da conduta e também para atingir aqueles convencidos de que dificilmente seriam responsabilizados por seus atos nas esferas administrativa, penal e civil.

Como nos casos de cativeiro, a denúncia representou um eficaz recurso do policiamento ambiental para que se conseguisse, com a informação de populares,

\footnotetext{
${ }^{21}$ CPIBIOPI, 2001,p. 379.

22 CERQUEIRA, Daniel e LOBÃO, Waldir. Determinantes da criminalidade: arcabouços teóricos e resultados empíricos. Dados- Revista de Ciências Sociais, v. 47, n. 2, 2004, p. 247.
} 
surpreender tanto aquele que tenta vender quanto aquele que busca comprar o objeto de crime. Além disso, o poder público passou a investir na prevenção por meio da possível conscientização dos cidadãos em campanhas de caráter educacional, com participação direta de policiais. Sem o adquirente, que é o final do processo, não existiria o interesse comercial que retroalimenta o ciclo vicioso.

Notoriamente, o erro de percepção se manteve durante décadas por uma herança cultural de apropriação dos recursos naturais manifesta, no caso da fauna, pelo hábito de possuir animal silvestre. A figura do "traficante" sempre foi associada àquele que caça, que transporta, que mantém em cativeiro e, por fim, àquele que vende, enquanto o comprador permanecia em uma posição isolada como figura passiva, envolvida no sistema mas absolvida pela falsa consciência de que "não há mal algum em possuir espécimes silvestres", ou pelo frágil argumento de que "enquanto se mantém determinado animal silvestre a propósito de estimação, se está cuidando bem dele e evitando que morra”, ou simplesmente pela errada noção de que "utilizar o espécime que já foi subtraído do meio natural não é crime"23.

Mesmo sem a sistematização de mecanismos de controle para mensuração dos resultados práticos da educação ambiental amplamente desenvolvida no período, firmou-se a percepção de que o ensino sobre a necessidade de uso sustentável dos recursos naturais possibilita a mudança de comportamentos potencialmente contrários ao meio ambiente.

\section{CONSIDERAÇÕES FINAIS}

Apesar de todo o esforço institucional alinhado às prioridades governamentais que sinalizaram a educação ambiental como um caminho certo, e o arcabouço legal respectivo que priorizou as ações preventivas para preservação do meio ambiente ecologicamente equilibrado, as infrações ambientais continuaram no período em estudo com elevada incidência. Deve-se reconhecer que especialmente 0 tráfico de animais silvestres

\footnotetext{
23 "Embora o hábito de 'adotar' espécimes da fauna silvestre brasileira advenha do Brasil Colônia, a fauna silvestre brasileira é legalmente propriedade do Estado desde a publicação da Lei oㅡ 5.197/67 (Lei de Proteção à Fauna). Segundo a Constituição Federal, compete à União, aos Estados e ao Distrito Federal legislar de modo complementar sobre fauna (art. 24, VI), sendo que preservá-la é competência comum desses entes e dos Municípios (art. 23, VII)" (BRASIL. Congresso Nacional. Relatório da Comissão Parlamentar de Inquérito destinada a investigar o tráfico de animais e plantas silvestres brasileiros, a exploração e comércio ilegal de madeira e a biopirataria no país - CPIBIOPI, 2006, op. cit., p. 381).
} 
prossegue associado à exploração da biodiversidade brasileira, não obstante o crescimento e a especialização das intervenções do policiamento ambiental junto com investimentos públicos e privados em educação ambiental.

Certo que a constatação de continuidade da prática criminal deve ser analisada em conjunto com outros fatores. O estudo dos registros disponíveis não é suficiente para concluir sobre ineficácia de todo o trabalho propriamente policial e das campanhas educativas, pois se consegue sempre medir a produtividade operacional que por sinal é objetivamente crescente (por exemplo, quantas prisões em flagrante foram realizadas em situações de tráfico de animais silvestres, ou quantos animais traficados foram apreendidos, ou quantas pessoas foram atingidas pela mensagem da educação ambiental), mas não se consegue identificar quantos crimes ambientais foram efetivamente evitados; nem há dados disponíveis para se definir em que proporção exata a fiscalização ou a educação ambiental são responsáveis pelos crimes ambientais não praticados.

Supõe-se, todavia, que a educação ambiental deverá influir muito positivamente sobre as novas gerações por ela alcançadas, com as mudanças culturais que se concretizam em um tempo maior do que aquele que os agentes policiais e educadores imaginam suficiente para esse fim. Basta recordar que até 1967 o ordenamento jurídico inclusive estimulava a comercialização de animal silvestre no Brasil, na medida em que bastava para tanto a existência de um simples registro na chamada Divisão de Caça e Pesca ${ }^{24}$.

Uma expressão de experientes policiais ambientais chama a atenção para a lentidão do processo de ruptura ou troca de paradigmas por eles observado: "percebemos que normalmente o filho de caçador é caçador; o filho de passarinheiro é passarinheiro" ${ }^{25}$. Será necessário superar essa relação de causalidade e, para tanto, o policial pode e deverá manter-se como agente de transformação na sociedade: um educador ambiental, além de fiscal do cumprimento da lei.

\footnotetext{
24 "Satisfeitas as exigências das instruções da Divisão de Caça e Pesca, poderão ser capturados e mantidos em cativeiro quaisquer animais silvestres" (artigo 11, parágrafo 1ํㅡㄹ do Decreto-Lei no 5.894, de 1943, Código de Caça que foi revogado pela Lei no 5.197, de 1967). Ainda, o mesmo Código de Caça de 1943 estipulava as várias formas de comercialização de animais, produtos e subprodutos da fauna silvestre, em seu artigo 32.

${ }^{25}$ Entrevista realizada com policiais militares ambientais da sede do $2^{\circ}$ BPAmb, em fevereiro de 2010.
} 
Sem abandono da indispensável ação repressiva, a manutenção de programas de educação ambiental indica um futuro de compromisso social e de exercício de cidadania, para a garantia do direito das próximas gerações quanto ao ambiente ecologicamente equilibrado, mediante uma clara proposta de valorização de todas as formas de vida e da preservação da fauna silvestre no seu próprio meio natural.

\section{REFERÊNCIAS}

BRASIL. Congresso Nacional. Relatório da Comissão Parlamentar de Inquérito destinada a investigar o tráfico ilegal de animais e plantas silvestres da fauna e flora brasileira CPITRAFI, 2003. Disponível em:<http://www.renctas.org.br/files/rel_fin_cp

itrafi_01_doc>. Acesso em: 10 jan. 2011.

- Congresso Nacional. Relatório da Comissão Parlamentar de Inquérito destinada a investigar o tráfico de animais e plantas silvestres brasileiros, a exploração e comércio ilegal de madeira e a biopirataria no país - CPIBIOPI, 2006. Disponível em: <http://www2.camara.gov.br/atividade-legislativa/comissoes/comissoes-temporarias/ parlamentar-de-inquerito/52-legislatura/cpibiopi/notas.html>. Acesso em: 11 jan. 2011.

CERQUEIRA, Daniel e LOBÃO, Waldir. Determinantes da criminalidade: arcabouços teóricos e resultados empíricos. Dados- Revista de Ciências Sociais, v. 47, n. 2, 2004.

IBAMA. Relatório a campanha nacional de proteção à fauna silvestre. Disponível em: <http://www.ibama.gov.br/fauna-silvestre/>. Acesso em: 08 fev. 2011.

NASSARO, Adilson Luís Franco. Aspectos jurídicos da busca pessoal. In: Revista A Força Policial, n. 44. São Paulo: PMESP, 2004, p. 41.

. Policiamento Rodoviário: cinquenta anos com sede regional em Assis. Assis: Triunfal. 2008.

CAES. 2008.

Busca em ônibus rodoviário: proposta de procedimento-padrão. São Paulo:

RENCTAS (ONG). Rede Nacional de Combate ao Tráfico de Animais Silvestres. Relatório Nacional sobre o Tráfico de Faunas Silvestres, com a colaboração do IBAMA, da Polícia Florestal, da Polícia Federal, das Secretarias do Meio Ambiente e do Ministério do Meio Ambiente, 2001. Disponível em: <http://www.renctas.org.br/pt/ trafico/default.asp>. Acesso em: 12 jan. 2011. 
SÃO PAULO (Estado) Governo do Estado de São Paulo. Secretaria Estadual do Meio Ambiente. Polícia Militar Ambiental. Tráfico de animais da fauna silvestre nacional: Dados Estatísticos e Estratégias Operacionais 2001 - 2005. São Paulo: Polícia Militar Ambiental, 2005.

SECRETARIADO DA CONVENÇÃO SOBRE DIVERSIDADE BIOLÓGICA. Panorama da Biodiversidade Global 3. Brasília: Ministério do Meio Ambiente, Secretaria de Biodiversidade e Florestas, 2010. Disponível em: <http://www.mma. gov.br/portalbio>. Acesso em: 13 mar. 2011.

2을. BPAmb. Página oficial. Disponível em: <http://www.polmil.sp.gov.br/unidades /cpamb/batalhao/2_batalhao/informacoes.htm>. Acesso em: 11 jul. 2011. 